\title{
LX. Contributions of the theory of the constitution of the diazoamido-compounds
}

\author{
Raphael Meldola F.R.S. F.I.C. F.C.S.
}

To cite this article: Raphael Meldola F.R.S. F.I.C. F.C.S. (1887) LX. Contributions of the theory of the constitution of the diazoamido-compounds, Philosophical Magazine Series 5, 23:145, 513-529, DOI: $10.1080 / 14786448708628046$

To link to this article: http://dx.doi.org/10.1080/14786448708628046

册 Published online: 29 Apr 2009.

Submit your article to this journal $\sqsubset \pi$

Џ Article views: 2

Q View related articles 


\section{$\left[\begin{array}{ll}513 & ]\end{array}\right.$}

LX. Contributions to the Theory of the Constitution of the Diazoamido-Compounds. By RapHael Meldola, F.R.S., F.I.C., F.C.S., Professor of Chemistry in the City and Guilds of London Institute, Finsbury Technical College*.

I $\mathrm{N}$ a series of investigations upon the diazoamido-compounds which have been carried out by me in conjunction with Mr. F. W. Streatfeild $\dagger$, certain facts have been brought to light which are quite inexplicable by any of the formulæ at present in use; and it has therefore become necessary to reconsider the whole question of the chemical constitution of these interesting derivatives, which have taxed to the utmost the ingenuity of all those chemists who have concerned themselves with their investigation.

The formula which up to the present time has been generally adopted is due to Kekulét, and is thus expressed in general terms :-

$$
\mathrm{X} \cdot \mathrm{N}_{2} \cdot \mathrm{NH} \cdot \mathrm{Y} \text {, }
$$

$\mathrm{X}$ and $\mathrm{Y}$ being similar or dissimilar radicals. The chief objection to this formula has hitherto been its asymmetrical character, which renders it incapable of explaining the remarkable observation of Griess $\S$, which is now confirmed from many sides, viz. that the mixed diazoamido-compounds, in which $\mathrm{X}$ and $\mathrm{Y}$ are dissimilar, are always identical whichever radical is first diazotized. This difficulty has been to some extent met by the suggestion of Victor Meyer\|; and in a former paper by Mr. Streatfeild and myself 9 it was shown that the results of our investigations, as far as these had been carried, could be explained by means of this hypothesis of the formation of intermediate additive compounds with a considerable show of reason.

The extension of our work has, however, forced me to the conclusion that Kekule's formula does not adequately express all the known facts concerning the diazoamido-compounds; and if this formula is, as I believe it must be, abandoned, the supplementary hypothesis is also rendered unnecessary.

The evidence which has led to the present theoretical

* Communicated by the Author.

$\dagger$ Journ. Ohem. Soc., Trans. 1886, p. 624; and 1887, p. 102.

$\ddagger$ Lehrbuch d. ory. Chem. vol. ii. pp. 689,715 , and 741 ; Zeit.f. Chem. 1866 , pp. 308,689 , and 700 .

$\S$ Ber. deut. chem. Gesell. vii. (1874), p. 1619.

II Ibid. xiv. (1881), p. 2447, note.

ๆ Journ. Chem. Soc., Trans. 1887, p. 116. 
discussion is briefly as follows :-By the action of diazotized metanitraniline upon paranitraniline an unsymmetrical diazoamido-compound is obtained, which has a melting-point of $211^{\circ}$. The same compound is obtained by reversing the order of combination, $i$. $e$. by acting upon metanitraniline with diazotized paranitraniline. According to Kekule's view, this substance could have only one of the two formulæ :-

I.

(p) $\mathrm{NO}_{2} \cdot \mathrm{C}_{6} \mathrm{H}_{4} \cdot \mathrm{N}_{2} \cdot \mathrm{NH} \cdot \mathrm{C}_{6} \mathrm{H}_{4} \cdot \mathrm{NO}_{2}(\mathrm{~m})$,

II.

(m) $\mathrm{NO}_{2} \cdot \mathrm{C}_{6} \mathrm{H}_{4} \cdot \mathrm{N}_{2} \cdot \mathrm{NH} \cdot \mathrm{C}_{6} \mathrm{H}_{4} \cdot \mathrm{NO}_{2}$ (p).

By replacing the $\mathrm{H}$-atom of the $\mathrm{NH}$-group by ethyl an ethyl-derivative (of m.p. 148 ${ }^{\circ}$ ) is formed; and this, on the same theory, could have only one of the two corresponding formulæ:-

III.

(p) $\mathrm{NO}_{2} \cdot \mathrm{C}_{6} \mathrm{H}_{4} \cdot \mathrm{N}_{2} \cdot \mathrm{N}\left(\mathrm{C}_{2} \mathrm{H}_{5}\right) \cdot \mathrm{C}_{6} \mathrm{H}_{4} \cdot \mathrm{NO}_{2}(\mathrm{~m})$,

IV.

(m) $\mathrm{NO}_{2} \cdot \mathrm{C}_{6} \mathrm{H}_{4} \cdot \mathrm{N}_{2} \cdot \mathrm{N}\left(\mathrm{C}_{2} \mathrm{H}_{5}\right) \cdot \mathrm{C}_{6} \mathrm{H}_{4} \cdot \mathrm{NO}_{2}(\mathrm{p})$.

If the unsymmetrical compound had the formula I., its ethyl-derivative (III.) might have been expected to be identical with the compound produced by the action of diazotized paranitraniline upon ethylmetanitraniline ; if it had the formula II., its ethyl-derivative (IV.) might have been expected to be identical with the compound produced by the action of diazotized metanitraniline upon ethyl-paranitraniline. As a matter of fact, it has been found that the ethyl-derivative of the unsymmetrical compound is identical with neither of the compounds prepared by the action of the diazotized nitranilines upon the ethyl-nitranilines. We have therefore to allow the existence of three isomeric ethyl-derivatives containing paraand metanitraniline residues, a fact which cannot be represented by Kekulé's formula. The properties of these and all the allied compounds prepared by us in the course of the inquiry are summarized in the following Table :- 
Constitution of the Diazoamido-Compounds.

\begin{tabular}{|c|c|c|c|c|c|c|c|c|c|}
\hline 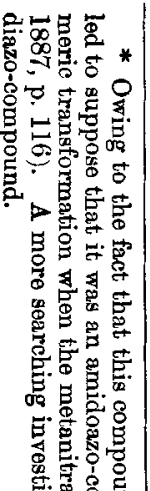 & 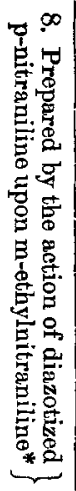 & 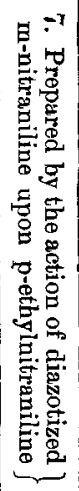 & 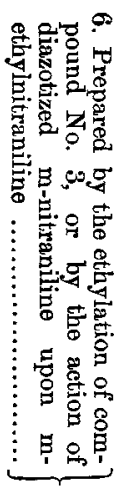 & 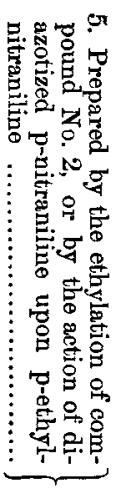 & 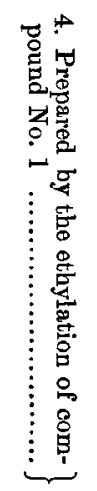 & 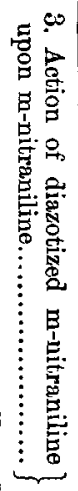 & 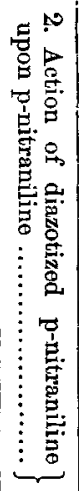 & 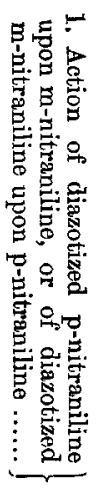 & 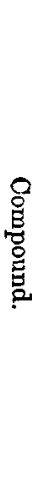 \\
\hline 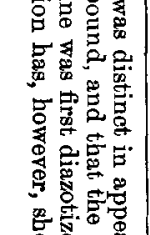 & $\begin{array}{l}\overrightarrow{0} \\
-1 \\
0\end{array}$ & $\begin{array}{l}\overrightarrow{7} \\
\text { fo } \\
\frac{1}{7} \\
\overrightarrow{0} \\
0\end{array}$ & छ & 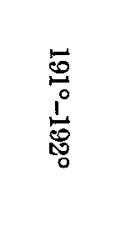 & 吾 & $\infty_{0}$ & ְ: & $\overrightarrow{\mathrm{o}}$ & 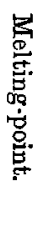 \\
\hline 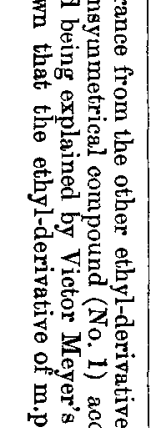 & 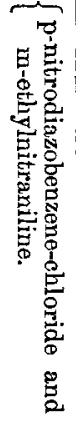 & 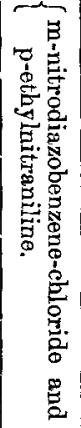 & 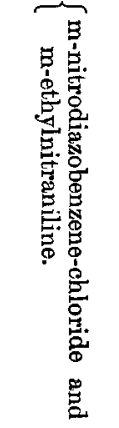 & 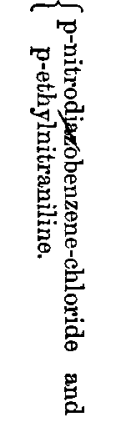 & 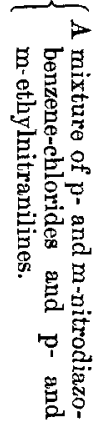 & 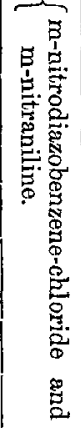 & 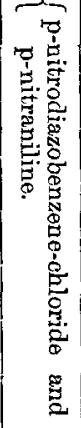 & 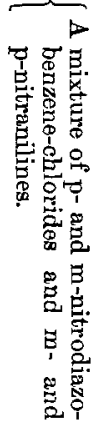 & 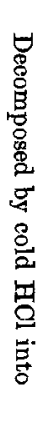 \\
\hline 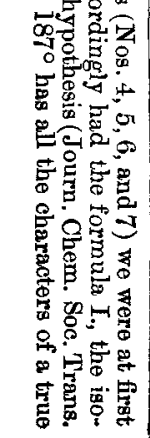 & 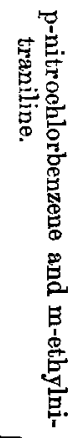 & 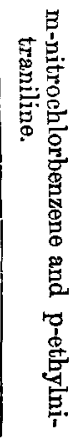 & 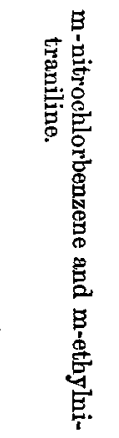 & 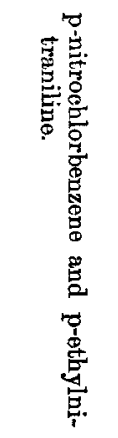 & 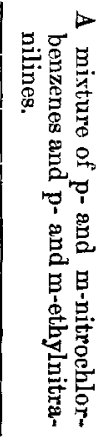 & 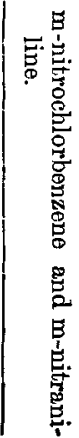 & 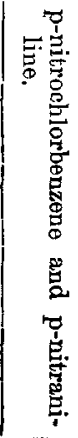 & 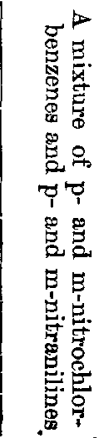 & 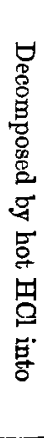 \\
\hline
\end{tabular}


If the ethyl-derivatives Nos. 7 and 8 are formulated on Kekule's type they would have the formulæ IV. and III. respectively, and thus no other expression is left for the ethylderivative No. 4.

The conditions to be fulfilled by any formula proposed for the diazoamido-compounds are, therefore, (1) that it should be symmetrical so as to represent the identity of mixed diazoamido-compounds, and (2) that it should be capable of representing more than two isomeric alkyl-derivatives of mixed compounds. These conditions are certainly not met by the formula now in use; and the objections which apply to this apply also to the alternative formula proposed by Strecker*:-

\section{X.N.NH.Y \\ $\dddot{\mathrm{N}}$}

This formula fails to explain the existence of more than two isomeric alkyl-derivatives of the unsymmetrical (mixed) compounds ; and is even less able than Kekulé's of representing the identity of mixed compounds, since it is incapable of the rearrangement suggested by Victor Meyer.

The first symmetrical formula proposed to explain the identity of mixed diazoamido-compounds is due to Griesst, the discoverer of these compounds, who suggested that diazoamidobenzene and its analogues should be written according to the type :-

$$
\begin{gathered}
\mathrm{C}_{6} \mathrm{H}_{4}=\mathrm{N}=\mathrm{N}=\mathrm{N}=\mathrm{C}_{6} \mathrm{H}_{4} \\
\dot{\mathrm{H}} \quad \dot{\mathrm{H}} \quad \dot{\mathrm{H}}
\end{gathered}
$$

This formula certainly explains the identity of mixed compounds, but is otherwise open to certain objections; since in the first place it represents diazoamidobenzene as a phenylene derivative, and in the next place it shows the presence of three $\mathrm{NH}$-groups containing three replaceable hydrogen atoms. All our experiments upon the salts and alkyl-derivatives of the dinitrodiazoamido-compounds have shown, however, that only one replaceable $\mathrm{H}$-atom is present $\ddagger$. This formula, moreover, is not capable of explaining the easy resolution of

* Ber. deut. chem.Gesell. iv. (1871), p. 786 ; Erlenmeyer, ibid. vii. (1874), p. 1110, and xvi. (1883) p. 1457. Also Blomstrand, ibid. viii. (1875), p. 51 .

$\dagger$ Ber. deut. chem. Gesell. x. (1877), p. 528.

$\mp$ These compounds give only monalkyl-derivatives; and the same appears to be the case with diazoamidobenzene, according to Messrs. Friswell and Green (Journ. Chem. Soc., Trans. 1886, p. 748), to whom I communicated the method of alkylization in the course of conversation, and who applied it to this compound successfully. 
diazoamido-compounds by acids, nor the production of mixed products from mixed compounds (see the foregoing Table).

Another symmetrical formula has been proposed by Victor Meyer*, viz.:-

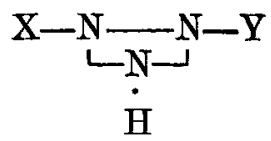

but this was abandoned by him as having but little probability. One of the greatest objections to this formula is that it fails to represent the $\mathrm{N}$-atom which is attached to the replaceable $\mathrm{H}$-atom as being also directly attached to one or the other of the aromatic radicals. The decomposition of the ethylderivatives of the dinitrodiazoamido-compounds by acids shows that this mode of attachment of the $\mathrm{NH}$-group certainly exists (see the foregoing Table).

In the course of the present investigations another symmetrical formula has suggested itself, which may be here given:-<smiles>[Y][Y]([H])([N+]#[X])[N+]#N</smiles>

This formula does not, however, appear to me to have any probability, as it fails to explain the decomposition of the diazoamido-compounds by acids, or the existence of isomeric alkyl-derivatives. Moreover, the formula of diazoamidobenzene written on this type:-

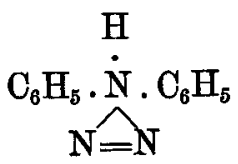

would indicate a close relationship between this substance and the remarkably stable diphenylamine. The latter is not found, however, among the reduction-products of diazoamidobenzene ; and there is no experimental evidence of any kind in favour of such a relationship.

Before proceeding to put forward my own views upon the constitution of these compounds it will be desirable to take a

* Ber. deut. chem. Gesell. xiv. (1881), p. 2447, note. 
general view of their characters, so as to gain a clear notion of all the conditions which have to be fulfilled by any proposed formula. These characters are summarized below, those compounds containing similar radicals being spoken of as "normal" compounds, and those containing dissimilar radicals as "mixed" compounds :-

(1) Normal compounds are prepared by diazotizing an amine, $\mathrm{X} . \mathrm{NH}_{2}$, and acting with the diazo-salt upon another molecule of the same amine, $\mathrm{X} . \mathrm{NH}_{2}$, or, what amounts to the same thing, one molecule of nitrous acid may be made to act upon two molecules of $\mathrm{X} . \mathrm{NH}_{2}$.

(2) Mixed compounds are obtained by diazotizing an amine, $\mathrm{X} . \mathrm{NH}_{2}$, and acting with the diazo-salt upon one molecule of another amine, $\mathrm{Y} . \mathrm{NH}_{2}$. The same compound results if the order of combination is reversed.

(3) The diazoamido-compounds, both mixed and normal, contain one atom of hydrogen easily replaceable by metals and alkyl radicals. If the aromatic radicals contain strongly acid groups (such as $\mathrm{NO}_{2}$ ), the resulting diazoamido-compounds may be distinct monobasic acids.

(4) Normal compounds are resolved by acids into their constituents, the diazo-salt and amine.

(5) Mixed compounds are resolved by acids into a mixture of the two bases from which they are derived, and a mixture of the two diazo-salts corresponding to these two bases.

(6) Alkyl derivatives of normal compounds may be prepared in two ways:-

a. By the action of a diazotized amine, $\mathrm{X} . \mathrm{NH}_{2}$, upon the alkylamine of the same base, $\mathrm{X}$. NHR.

$\beta$. By the direct alkylization of the normal diazoamidocompound.

(7) The alkyl-derivatives of normal compounds are decomposed by acids into their constituents, the diazo-salt and alkylamine.

(8) Alkyl-derivatives of mixed diazoamido-compounds are formed by the direct alkylization of these compounds (see group 2).

(9) Another group of mixed alkyl-derivatives can be prepared by the action of a diazotized amine, $\mathrm{X} . \mathrm{NH}_{2}$, upon the alkyl-derivative of a dissimilar amine, Y.NHR. These compounds are isomeric with those of the preceding group.

(10) Mixed alkyl-derivatives of group (8) are resolved by the action of acids into a mixture of the two diazo-salts and the two alkylamines. 
(11) Mixed alkyl-derivatives of group (9) are resolved by acids into their constituents, the diazo-salt and the alkylamine, but not into a mixture of diazo-salts and alkylamines, as is the case with the compounds of group $9^{*}$.

(12) Normal compounds, by the action of weak reducing agents, are reduced to the original amine $\mathrm{X} . \mathrm{NH}_{2}$, and the hydrazine $\mathrm{X} \cdot \mathrm{N}_{2} \mathrm{H}_{3}$. Mixed compounds give, on reduction, the base $\mathrm{X} . \mathrm{NH}_{2}$ and the hydrazine $\mathrm{Y} . \mathrm{N}_{2} \mathrm{H}_{3}$, or the base $\mathrm{Y} . \mathrm{NH}_{2}$ and the hydrazine $\mathrm{X} \cdot \mathrm{N}_{2} \mathrm{H}_{3} \dagger$.

(13) Alkyl-derivatives of normal compounds reduce to the hydrazine $\mathrm{X} . \mathrm{N}_{2} \mathrm{H}_{3}$ and the alkylamine $\mathrm{X}$. NHR $\ddagger$. Alkylderivatives of mixed compounds give, on reduction, the hydrazine $\mathrm{X}$ - or $\mathrm{Y} . \mathrm{N}_{2} \mathrm{H}_{3}$, and the alkylamine $\mathrm{Y}$ - or $\mathrm{X}$. NHR This production of alkylamines indicates that the $\mathrm{N}$-atom which is in combination with the alkyl-radical is also attached to the aromatic nucleus $\|$.

From the foregoing summary it will be seen that the mixed diazoamido-compounds and their alkyl-derivatives display the most striking characters, and are of special importance to the present discussion, because it is in the attempt to formulate these compounds on Kekule's plan that the greatest difficulties are encountered. In view of the objections which apply to all the formula hitherto proposed it has been no easy matter to suggest any alternative formula ; but I believe that the true solution of the problem will be arrived at by regarding phenyl as a triatomic radical, $\mathrm{C}_{6} \mathrm{H}_{5}^{\prime \prime \prime}$, instead of monatomic, as has always been assumed in previous formulæ. This suggestion is in accordance with Fittig's theory of the constitution of

* To this class, in addition to the ethyl-derivatives of m.p. $174^{\circ}-175^{\circ}$ and $187^{\circ}$ (Nos. 7 and 8 in the Table), belong the two following compounds:(1) produced by the action of diazotized p-toluidine upon ethylaniline, and (2) prepared by the action of diazotized aniline on ethyl-p-toluidine. These two compounds are isoneric; the first being decomposed by acids (hot) into p-cresol and ethylaniline, and the second into phenol and ethyl-p-toluidine (Nölting and Binder, Bull. Soo. Chim. vol. xlii. p. 341 ; Gastiger, ibid. p. 342). This pair of isomerides is completely analogous to our two ethyl-derivatives (Nos. 7 and 8), which they resemble in their mode of decomposition.

$\dagger$ Thus the compound produced by the action of diazotized aniline upon p-toluidine or the reverse gives, on reduction, phenylhydrazine and p-toluidine (Nölting and Binder, loc. cit. p. 336).

$\mp$ Thus the compound obtained by the action of diazotized aniline on methylaniline reduces to phenylhydrazine and methylaniline (loc. cit.).

$\$$ Thus the compound prepared by Gastiger by the action of diazotized aniline on ethyl-p-toluidine reduces to phenylhydrazine and ethyl-ptoluidine (loc. cit. p. 342).

$\|$ The presence of substituents in one or both aromatic radicals may interfere with the formation of hydrazines; in such cases the corresponding substituted amines are formed, or, if the substituent is $\mathrm{NO}_{2}$, the corresponding diaminer. 
quinone, this compound being regarded by him as a double ketone:-<smiles>O=C1C=CC(=O)C=C1</smiles>

Phenylene, according to this view, must be regarded as a tetratomic radical, and a slight extension of the same view enables us to consider phenyl as triatomic:-<smiles>C=CC1CCCCC1C=C</smiles><smiles>C=CC=CC</smiles>

If this assumption be made, it then becomes possible to construct formulæ for the mixed diazoamido-compounds which meet all the requirements of the case, and which must, therefore, commend themselves to the notice of all chemists who, like myself, have been puzzled to explain the behaviour of these compounds in accordance with the existing theoretical notions. The formula now proposed may bo written in two ways:-

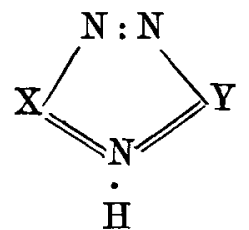

I.

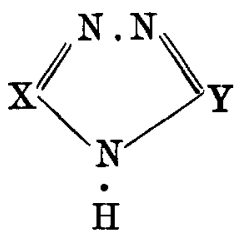

II.

Of these two formulæ $\mathrm{I}$ am disposed to attach the greater weight to the first because it indicates the presence of the very stable azo-group, $-\mathrm{N}: \mathrm{N}-$; and this is in accordance with the general character of the compounds, which decompose under the influence of acids or of reducing agents in such a manner that the $\mathrm{N}$-atoms of the azo-group always remain in combination, either in the form of a diazo-salt or a hydrazine. On the other hand, the second formula indicates the presence of the group $=\mathrm{C}=\mathrm{N} \cdot \mathrm{N}=\mathrm{C}=$; and this might 
be expected to split asunder between the $\mathrm{N}$-atoms more readily on reduction or on decomposition by acids than is shown to be the case by experiment.

According to the proposed formula the unsymmetrical compound of m.p. $211^{\circ}$ (No. 1 in the table) and its ethylderivative of m.p. 148 (No. 4 in the table) would be thus written:-

$$
\text { (p) } \mathrm{NO}_{2} \cdot \mathrm{C}_{6} \mathrm{H}_{4}
$$

It may now be pointed out how far these formulæ are in harmony with the known characters of the mixed diazoamidocompounds. In the first place it is obvious that the formula is symmetrical, and thus explains the identity of the compounds irrespective of the order of combination. Putting $P$ for the $\mathrm{p}$-nitraniline residueand $\mathrm{M}$ for the $\mathrm{m}$-nitraniline residue, this fact may be thus represented without assuming the formation of any intermediate additive compound:-

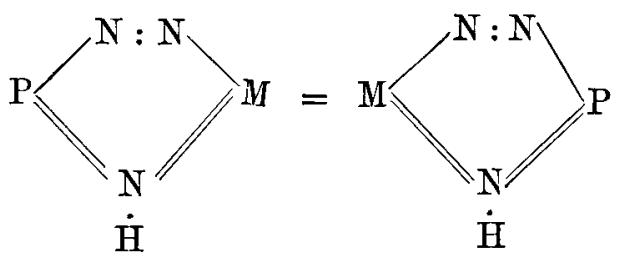

Consider in the next place the decomposition by hydrochloric acid :-
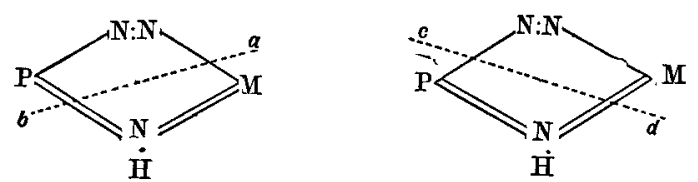

If separation took place along the line $a b$, the products would Phil. Mag. S. 5. Vol. 23. No. 145. June 1887. $2 \mathrm{~N}$ 
be p-nitrodiazobenzene-chloride and m-nitraniline ; along $c d$, the products would be m-nitrodiazobenzene-chloride and pnitraniline. As a matter of fact all four products are obtained, so that decomposition must take place in both directions. The same explanation obviously applies to the mixed decomposition-products of the ethyl-derivative. Again, the formula shows the presence of the one replaceable $\mathrm{H}$-atom in combination with the $\mathrm{N}$-atom which is attached to the aromatic radicals. The question of the existence of more than two isomeric alkyl-derivatives will be considered subsequently.

The formula which has now been suggested for the mixed diazoamido-compounds derived from $\mathrm{p}$ - and m-nitraniline can be applied with equal success to all other mixed compounds. Thus, to take examples of those compounds whose products of decomposition have been studied:-

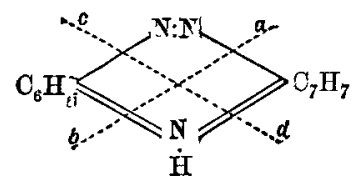<smiles>CCC(=O)c1nnc(Sc2ccccc2)[nH]1</smiles>

Both these compounds were discovered and their decomposition products studied by Griess : the first is obtained by the action of diazotized aniline upon p-toluidine, or of diazotized p-toluidine upon aniline; the second is similarly produced from aniline and amidobenzoic acid. When heated with acids the first compound gives a mixture of aniline, p-toluidine, phenol, and p-cresol (Nölting and Binder) ${ }^{*}$; and the second compound under similar circumstances gives aniline, phenol, oxybenzoic, and amidobenzoic acid (Griess). The products in these cases indicate separation along both planes of decomposition $a b$ and $c d$.

The explanation of the existence of more than two isomeric alkyl-derivatives of mixed diazoamido-compounds is closely connected with the question whether the new formula can be applied to the normal diazoamido-compounds. The following considerations will show that these compounds cannot be formulated on the new type:-

As a type of the normal compounds let us consider that derived from p-nitranilins (No. 2 in the table). If this had the new formula it (and its ethyl-derivative) would have to be written:-

* This compound reduces to phenyl-hydrazine and p-toluidine, thus indicating a preference of the $\mathrm{N}_{2}$ - (and therefore the $\mathrm{NH}-\mathrm{NH}_{2}$ ) group to remain attached to the more positive radical. The separation is in this case along $a b$ only. 

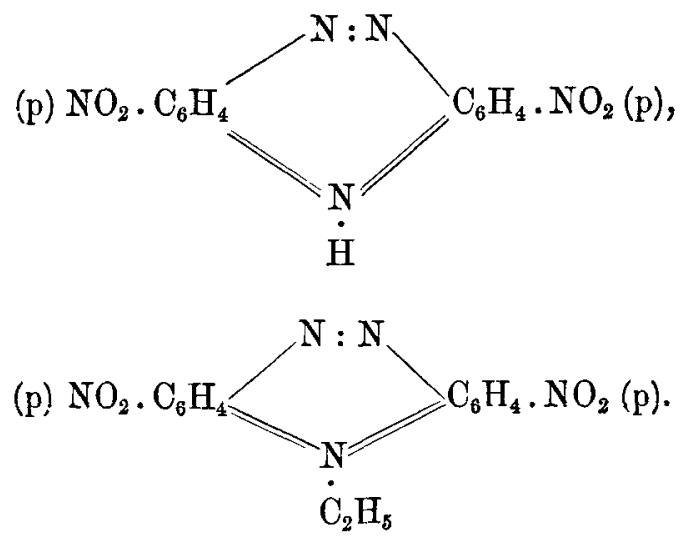

Now the ethyl-derivative (No. 5 in the table) is prepared by the direct ethylation of the compound itself, and also by the aetion of diazotized p-nitraniline upon p-ethylnitraniline. Analogy would therefore lead us to suppose that if the ethylderivative had the above constitution, the other ethyl-derivatives, prepared by the action of diazotized p-nitraniline upon m-ethylnitraniline (m.p. $187^{\circ}$ ) and of diazotized m - nitraniline upon p-ethylnitraniline (m.p. $174^{\circ}-175^{\circ}$ ), would have a similar constitution:-

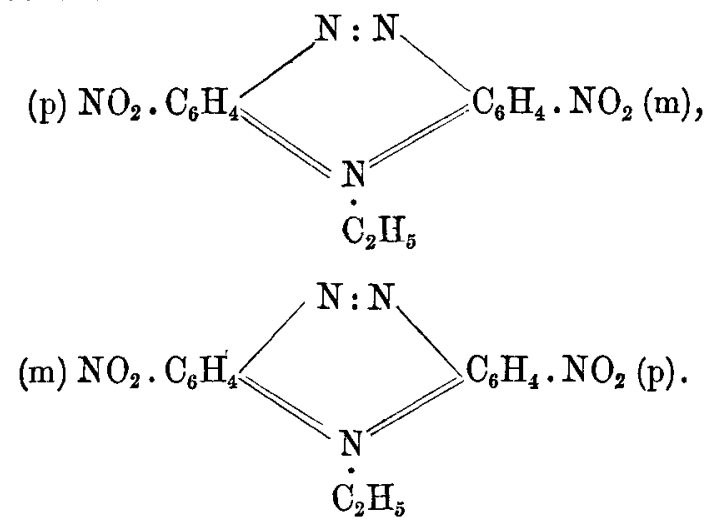

But these two formula are identical with one another and with that of the ethyl-derivative of m.p. $148^{\circ}$, whereas their melting-points and mode of decomposition show most conclusively that the three compounds are isomeric and not identical. It must, therefore, be concluded that the formula now proposed does not apply to the normal compounds, and the suggestion at once arises whether these may not be the 
true representatives of Kekule's type. In answer to this I may point out that, as far as the experimental evidence at present goes, the normal compounds and the analogous ethylderivatives may be written on Kekule's type:-

$$
\begin{aligned}
& \text { (p) } \mathrm{NO}_{2} \cdot \mathrm{C}_{6} \mathrm{H}_{4} \cdot \mathrm{N}_{2} \cdot \mathrm{NH} \cdot \mathrm{C}_{6} \mathrm{H}_{4} \cdot \mathrm{NO}_{2}(\mathrm{p}) \text {, } \\
& \text { m.p. } 223^{\circ} \text {. } \\
& \text { (m) } \mathrm{NO}_{2} \cdot \mathrm{C}_{6} \mathrm{H}_{4} \cdot \mathrm{N}_{2} \cdot \mathrm{NH} \cdot \mathrm{C}_{6} \mathrm{H}_{4} \cdot \mathrm{NO}_{2}(\mathrm{~m}) \text {, } \\
& \text { m.p. } 194^{\circ} \text {. } \\
& \text { (p) } \mathrm{NO}_{2} \cdot \mathrm{C}_{6} \mathrm{H}_{4} \cdot \mathrm{N}_{2} \cdot \mathrm{N}\left(\mathrm{C}_{2} \mathrm{H}_{5}\right) \cdot \mathrm{C}_{6} \mathrm{H}_{4} \cdot \mathrm{NO}_{2}(\mathrm{p}) \text {, } \\
& \text { m.p. } 191^{\circ}-192^{\circ} \text {. } \\
& \text { (m) } \mathrm{NO}_{2} \cdot \mathrm{C}_{6} \mathrm{H}_{4} \cdot \mathrm{N}_{2} \cdot \mathrm{N}\left(\mathrm{C}_{2} \mathrm{H}_{5}\right) \cdot \mathrm{C}_{6} \mathrm{H}_{4} \cdot \mathrm{NO}_{2}(\mathrm{~m}) \text {, } \\
& \text { m.p. } 119^{\circ} \text {. } \\
& \text { (p) } \mathrm{NO}_{2} \cdot \mathrm{C}_{6} \mathrm{H}_{4} \cdot \mathrm{N}_{2}: \mathrm{N}\left(\mathrm{C}_{2} \mathrm{H}_{5}\right) \cdot \mathrm{C}_{6} \mathrm{H}_{4} \cdot \mathrm{NO}_{2}(\mathrm{~m}) \text {, } \\
& \text { m.p. } 187^{\circ} \text {. } \\
& \text { (m) } \mathrm{NO}_{2} \cdot \mathrm{C}_{6} \mathrm{H}_{4} \cdot \mathrm{N}_{2} \mathrm{~N}\left(\mathrm{C}_{2} \mathrm{H}_{5}\right) \cdot \mathrm{C}_{6} \mathrm{H}_{4} \cdot \mathrm{NO}_{2}(\mathrm{p}) \text {. }
\end{aligned}
$$

The modes of decomposition of these compounds are explained by the above formula by supposing the planes of separation to be along the dotted lines; and it further appears that the isomerism of the three ethyl-derivatives of m.p's $148^{\circ}$, $174^{\circ}-175^{\circ}$, and $187^{\circ}$ (Nos. 4,7 and 8 in the table) may be explained by the different formula ascribed to these compounds respectively.

But although Kekulé's formula may pass muster for the normal compounds, we are not necessarily reduced to this as a final expression; and I am strongly inclined to the belief that it will have to be abandoned also in the case of these compounds. In the first place, as there is a great resemblance in character between the normal and the mixed compounds, analogy leads me to suppose that their constitutions are not so widely different, as appears from the two modes of formulation :-

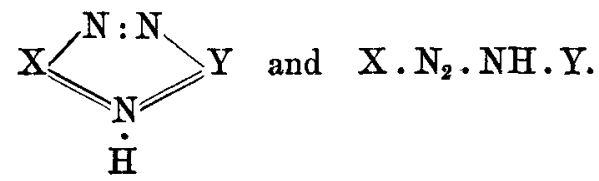


In the next place the group $-\mathrm{N}=\mathrm{N}-\mathrm{NH}-$ assumed to be present, according to the prevailing view, has always seemed to me to be a most improbable arrangement of $\mathrm{N}$ atoms, and without any analogy among chemical compounds. Those compounds in which three combined $\mathrm{N}$-atoms are present are only stable when the $N$-atoms form a closed chain, as in Griess's benzeneimide :-

$$
\mathrm{C}_{6} \mathrm{H}_{5} . \mathrm{N}<\ddot{\mathrm{N}},
$$

or in the azimidobenzene of this same author*:-

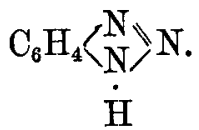

From these considerations I am led to conclude that an open chain of three nitrogen atoms does not exist in any of the diazoamido-compounds, and the remarkable stability of the dinitrodiazoamido-compounds in the presence of alkalis $\dagger$ certainly supports this view.

The formula which $I$ now venture to suggest for the normal compounds is, as far as I can see, at any rate as equally capable as Kekule's of representing the characters of these compounds, and at the same time indicates the analogy of these to the normal compounds. It has moreover the advantage of doing away with the assumption of the open chain of N-atoms :-

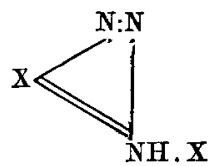

According to this formula the preceding compounds would be written :-

* I have accepted this formula rather than the alternative one $\mathrm{C}_{6} \mathrm{H}_{4} \mathrm{~N}_{\mathrm{NH}} \mathrm{NH}$, because, according to Boessneck (Ber. xix. 1886, p. 1757), acetorthotoluylene-diamine yields acetazimidotoluene by the action of nitrous acid. 'The $\mathrm{N}, \mathrm{C}_{2} \mathrm{H}_{3} \mathrm{O}$-group must, therefore, be attached to the aromatic nucleus, and this acetyl compound gives azimidotoluene by hydrolysis, so that the NH-group must also be attached to the aromatic nucleus.

+ These compounds can be boiled with strong potash solution for days without undergoing any alteration (Journ. Chem. Soc., Trans. 1886, p. 627). Even the simpler compounds like diazoamidobenzene are much more stable in neutral or alkaline solutions than is generally supposed. 
(p)

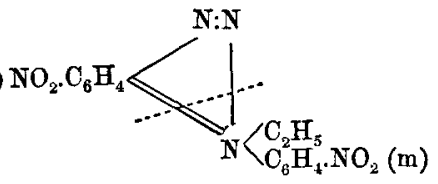

m.p. $187^{\circ}$. (p or $\mathrm{m}$ ) $\mathrm{NO}_{2} \cdot \mathrm{C}_{3} \mathrm{H}_{4}$

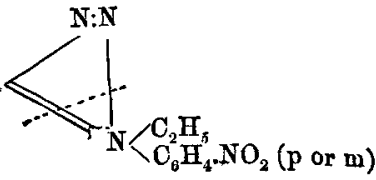

(m) $\mathrm{NO}_{2} \cdot \mathrm{O}_{6} \mathrm{H}_{4}$

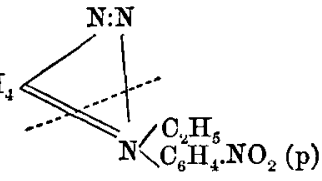

m.p. $174^{\circ}-175^{\circ}$. lines.]

[The planes of decomposition are represented by the dotted

It will readily be seen that these formula are in harmony with the characters of the/compounds which they represent. Thus, taking the products of decomposition of the last pair of isomeric ethyl-derivatives, the $187^{\circ} \mathrm{m} . \mathrm{p}$. modification is resolved into p-nitrodiazobenzene-chloride and m-ethylnitraniline, while the other modification yields m-nitrodiazobenzenechloride and p-ethylnitraniline.

The corresponding pair of isomeric ethyl-derivatives containing aniline and toluidine residues, prepared by Nölting and Binder and by Gastiger, may be similarly formulated :-

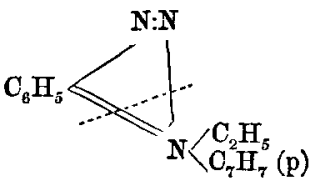

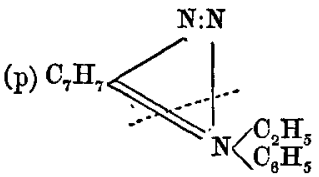

These compounds, which have already been referred to, are decomposed by acids (hot); the first into phenol and p-ethyltoluidine, and the second into p-cresol and ethylaniline.

The mixed compounds containing both aromatic and fatty radicals are in all respects analogous to the normal compounds, and, according to Wallach*, behave like these on decomposition. Thus the typical compounds of this group, first prepared by Baeyer and Jäger $\dagger$ by the action of diazobenzene salts upon ethylamine, dimethylamine, and piperidine, may be written :-<smiles>CCNNC12CCCCC1(C)C2(C)NCC</smiles>

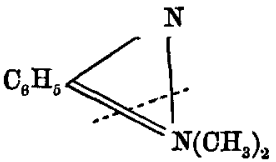

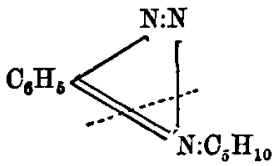

* Lieb. Ann. rol. ccxxxv. p. 233.

$\dagger$ Ber. deut. chem. Gesell. viii. (1875) pp. 148, 893. 
A few remarks may here be made in connexion with the transformation of diazoamido- into amidoazo-compounds. It has always been supposed hitherto that this transformation is preceded by a resolution of the diazoamido-compound into its constituents *. This may be the case in the presence of excess of acid; but it is doubtful whether such a resolution occurs when the diazoamido-compound (say diazoamidobenzene) is allowed to stand in the presence of excess of aniline containing only a small quantity of aniline hydrochloride. It is well known, however, that such a mixture will effect the complete conversion of diazoamido- into amidoazobenzene in the course of a few hours, especially if aided by heat. If the formula of diazoamidobenzene is written according to the present view, it will be seen that a slight rearrangement of the "bonds" would convert it into a symmetrical compound of the type already proposed for the mixed diazoamido-compounds; thus :-
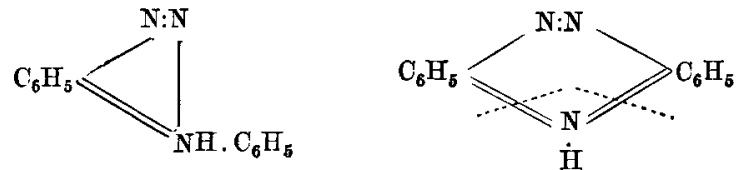

It seems not improbable that such a symmetrical compound may precede the formation of amidoazobenzene, the separation (accompanied by the migration of the $\mathrm{H}$-atom to the $\mathrm{NH}$ group $)$ occurring along one of the dotted lines.

Altbough the formulæ now proposed for the normal diazoamido-compounds appear capable of meeting all the requirements of the case, it will be of interest to point out that other molecular arrangements in which phenyl functions as a triatomic radical are possible :-

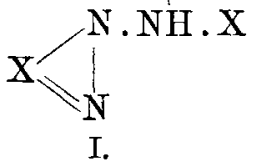

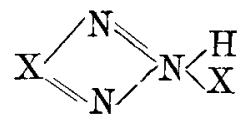

II.<smiles>[Y][N+]1=[V]N1</smiles>

III.

* See the last contribution to this question by Wallach (Lieb. Ann. vol. cexxxv. p. 238). I am bound to express the opinion, however, that the suggestion there thrown out does not materially add to the solution of the problem (Proc. Chem. Soc. 1887, p. 27).

+ Such a transference of hydrogen is analoxous to that which takes place when hydrazobenzene, $\mathrm{C}_{6} \mathrm{H}_{5}$. NH $. \mathrm{NH} . \mathrm{C}_{6} \mathrm{H}_{5}$, is converted into benzidine, $\mathrm{NH}_{2} \cdot \mathrm{C}_{6} \mathrm{H}_{4} \cdot \mathrm{C}_{6} \mathrm{H}_{4} \cdot \mathrm{NH}_{2}$, by the action of acids. No previous resolution into constituents has ever been supposed in this case. The transformation appears rather to be of the nature of a rotation of the benzene rings, and there is reason for believing that a similar rotation takes place in the decomposition of nixed diazoamido-compounds by acids. This point cannot be discussed, however, until the evidence is more complete. 
All these formulæ are, however, more or less open to objection, and need not be further discussed at present. It will suffice to mention that No. III., which at first sight might appear the most probable of the three, is incapable of representing such compounds as diazobenzenedimethylamide.

The views now advanced concerning the constitution of this interesting group of compounds open up suggestive lines of investigation in the direction of isomerism as connected with position. In the formula representing phenyl as a triad radical previously given, the free bonds have been represented in the para-position, because the ortho-quinone of the benzene series does not appear to be capable of existence. But the formula obviously allows the possibility of such an orthoarrangement:-

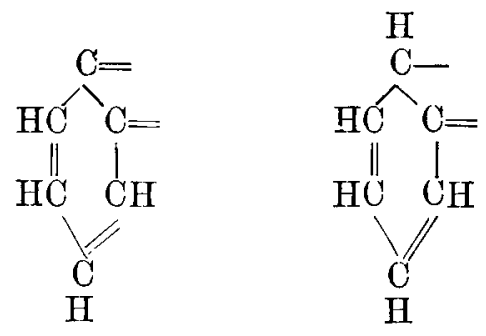

The para-position of the substituents is, however, in harmony with the known behaviour of diazoamidobenzene, the isomeric amidoazobenzene having its substituents in the paraposition. It seems probable, therefore, if there is anything in the previously expressed view concerning this isomeric transformation, that at least in this diazoamido-compound the substituents $-\mathrm{N}: \mathrm{N}-$ and $=\mathrm{NH}=$ are in the paraposition.

Summing up the general results of the present discussion, it appears to me that the formula now proposed for the mixed diazoamido-compounds is the only one that has hitherto been in harmony with all the known characters of these compounds, and as such it is at any rate worthy of serious consideration by chemists. Analogy leads to the belief that the normal compounds have a similar, or at least a partly similar constitution; but the evidence is not so satisfactory in these cases, owing to the similarity of the two halves of the molecule, which renders it impossible to follow the course of decomposition with the same certainty as in the mixed compounds. Before, however, the whole question of the constitution of the diazoamido-compounds can be completely worked out on the lines here suggested, it will be necessary to have a 
much larger body of experimental evidence. Further investigations in the required direction are now in progress in the laboratory of the Finsbury Technical College.

Postscript.- Since writing the foregoing paper, the detailed evidence which has led to the conclusion that the ethylderivative of m.p. $187^{\circ}$ is a diazo-compound has appeared in a communication to the Chemical Society (Journ. Chem. Soc., Trans. 1887, p. 434). Additional evidence of the production of mixed compounds on the decomposition of mixed diazoamidoderivatives is given in a recent paper by Heumann and Oeconomides (Ber. 1887, p. 904). These authors find that the mixed compound $\mathrm{C}_{6} \mathrm{H}_{5} \cdot \mathrm{N}_{3} \mathrm{H} \cdot \mathrm{C}_{7} \mathrm{H}_{7}$, on being heated with phenol, gives a mixture of aniline and p-toluidine together with oxyazobenzene and p-tolueneazophenol.

LXI. On the Stability of Steady and of Periodic Fluid Motion (continued from May number).-Maximum and Minimum Energy in Vortex Mlotion*. By Sir William Thomson, F.R.S.

10. THE condition for steady motion of an incompressible 1 inviscid fluid filling a finite fixed portion of space (that is to say, motion in which the velocity and direction of motion continue unchanged at every point of the space within which the fluid is placed) is that, with given vorticity, the energy is a thorough maximum, or a thorough minimum, or a minimax. The further condition of stability is secured, by the consideration of energy alone, for any case of steady motion for which the energy is a thorough maximum or a thorough minimum ; because when the boundary is held fixed the energy is of necessity constant. But the mere consideration of energy does not decide the question of stability for any case of steady motion in which the energy is a minimax.

11. It is clear $\dagger$ that, commencing with any given motion, the energy may be increased indefinitely by properly-designed operation on the boundary (understood that the primitive boundary is retarned to). Hence, with given vorticity, but with no other condition, there is no thorough maximum of energy in any case. There may also, except in the case of irrotational circulation in a multiplexly continuous vessel

* Being a communication read before the British Association, Section A, at the Swansea Meeting, Saturday, August 28, 1880, and published in the Report for that year, p. 473 ; and in 'Nature,'Oct. 28, 1880. Reprinted now with corrections, amendments, and additions.

$\dagger$ See also $\$ \S 3$ to 9 above. 